Elsig, J., Schmitt, J., Leuenberger, D., Schneider, R., Eyer, M., Leuenberger, M., Joos, F., Fischer, H. and Stocker, T., 2009: Stable isotope constraints on Holocene carbon cycle changes from an Antarctic ice core, Nature, 461: 507-510.
Monnin, E., Indermühle, A., Dällenbach, A., Flückiger, J., Stauffer, B., Stocker, T., Raynaud, D. and Barnola, J.-M., 2001: Atmospheric $\mathrm{CO}$ concentrations over the last glacial termination, Science, 291: $112-114$.
Flückiger, J., Monnin, E., Stauffer, B., Schwander, Stocker, T., Chappellaz, J., Raynaud, D. and Barnola, J.-M., 2002: High-resolution Holocene $\mathrm{N}, 0$ ice core record and its relationship with $\mathrm{CH}_{2}$ and $\mathrm{CO}_{2}, \mathrm{Global}$ Bíogeochemical Cycles, 16: 1010, doi:10.1029/2001GBo01417.

\title{
Towards a global synthesis of the climate of the last two
} millennia

\section{Workshop of the PAGES 2k Regional Network - Corvallis, USA, 7 July 2009}

\author{
Louise Newman ${ }^{1}$, H. WAnner ${ }^{2}$ and T. Kiefer ${ }^{1}$
}

1PAGES International Project Office, Bern, Switzerland; newman@pages.unibe.ch

²Oeschger Centre for Climate Change Research and Institute of Geography, University of Bern, Switzerland; heinz.wanner@giub.unibe.ch

Research on the last 1-2 ka has resulted in several multi-proxy reconstructions of global and hemispheric temperature, and other climatic parameters (e.g., Rutherford et al., 2005; Mann et al., 2006; 2008; Luterbacher et al., 2004). Despite this, we still do not sufficiently understand the precise sequence of changes related to regional climate forcings, internal variability, system feedbacks, and the responses of surface climate, land-cover, biosphere and hydrosphere. Furthermore, many parts of the globe lack adequate paleorecords for comparison with model simulations, and high-resolution instrumental datasets are sparse.
To address these knowledge gaps, PAGES developed the Regional 2k Network-a set of Working Groups (WGs) that collect and process the best available time series and spatial reconstructions of important climate system variables for a given region (including the adjacent ocean; Fig. 1). Several WGs built on existing projects and are, therefore, at a mature stage in their research, while other WGs have only recently formed. All the WGs recently came together for a one-day workshop in Corvallis, USA to discuss regional results, exchange information on approaches and techniques, and develop a coordinated strategy for outcomes and syntheses.

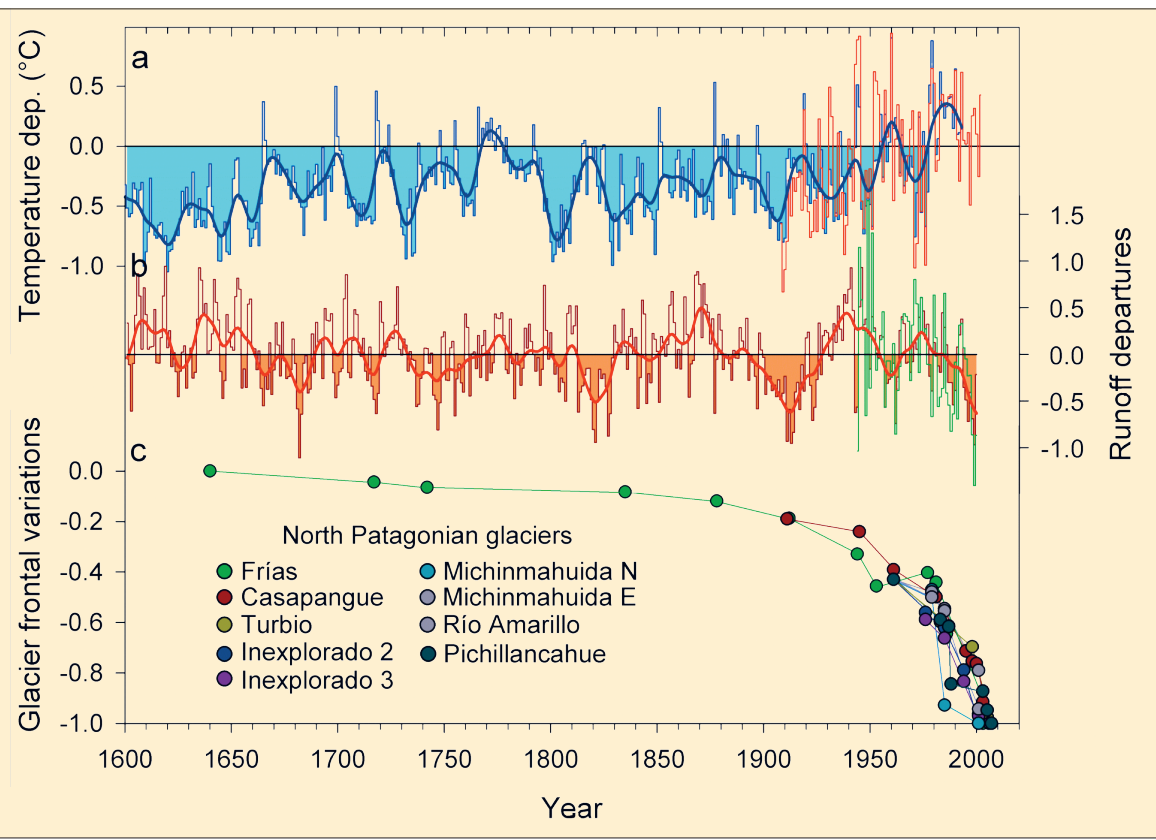

Figure 1: Recent results from the LOTRED-South America 2k effort. Climate variations in the Northern Patagonian Andes during the past four centuries. a) Summer (Nov - Mar) temperature changes (expressed as departure from calibration period 1908-2003) inferred from a regional network of Fitzroya cupressoides tree-ring chronologies in northern Patagonia (blue line; Villalba et al.,2006) plotted with the instrumental summer temperature variations for northern Patagonia (red line; Jones and Moberg, 2003) for the interval 1908-2003. The correlation coefficient observed v's reconstructed is $r=0.75(n=85, p<0.01)$. $\boldsymbol{b}$ ) Tree-ring based reconstruction of Dec-May stream flow deviations (expressed as departure from calibration period 1943-1999) of Río Puelo from 1599 to 1999 developed from a combination of Austrocedrus chilensis and Pilgerodendron uviferum chronologies (red line; Lara et al., 2008). It correlates significantly with the instrumental Rio Puelo stream flow recorded at Carrera Basilio, Chile (green line) for the period 1943-1999, at 99\% confidence level ( $r=0.65$ ). Thick lines in both a and b represent 15-year cubic splines to emphasize low frequency variations in the reconstructions. c) Frontal variations of selected glaciers in the North Patagonian Andes. Total retreat of the glacier with the longest record (Glaciar Frias; AD 1660-2007) was normalized to -1.0 and the frontal variations of the other glaciers were adjusted to this range of variation. Glacier frontal variations are from Villalba et al., (1990), Bown and Rivera (2007), and Masiokas et al. (2008; 2009). The thin interpolation-lines in (c) are drawn to enhance the readability and do not suggest linear trends between two data points.
Following an introductory talk by Heinz Wanner, the state-of-the-science for each group was presented. Representing Europe and the Mediterranean, Jürg Luterbacher presented a compilation of annual- and lower-resolution proxy records, and highlighted efforts towards spatial reconstructions and associated uncertainty estimates for a dynamical understanding of European climate. The focus of this WG now is to push the temporal scale of spatial reconstructions to cover $2 \mathrm{ka}$, combining all available proxies, data-model comparison and data assimilation exercises.

The North American WG is also well placed to move towards synthesis. Caspar Ammann highlighted the extensive network of proxy records available and outlined new methodological advances that will provide greater understanding of the physical mechanisms behind past climatic changes. Future goals of this WG are to produce a review of the available data and to cross validate with model output.

A concerted South American effort has resulted in a recently published series of regional syntheses of data sets from a variety of paleoclimate archives (see details on website). Ricardo Villalba presented an overview of these results, and showed that the spatial and temporal coverage of the data is adequate to develop multi-proxy field reconstructions for southern South America for the past ca. 500 years. Efforts are now being directed towards homogenizing instrumental data sets for calibration of proxy data series, and increasing their temporal and spatial coverage.

The Asia 2k WG is under development. Edward Cook presented multi-proxy reconstructions of the Asian monsoon, temperature and drought from Eastern Asia, the Altay Mountains and Indochina, respectively. The next step for this group is to consolidate the team, followed by a review of the available data and gaps in knowledge. 
The African 2k WG is also still developing. Mohammed Umer and David Nash presented an overview of available data for Eastern and Southern Africa, respectively, particularly highlighting the importance of understanding variations in rainfall and occurrence of extreme events (e.g., droughts). Once group participants are finalized, this WG will undertake a review and integration of high-resolution time series.

The Australasian $2 \mathrm{kWG}$ is moving forward following a workshop in 2005 and a resulting synthesis special issue. Joëlle Gergis presented a new temperature reconstruction for the region covering the last $\sim 500$ years, and highlighted new efforts to reconstruct regional temperature, precipitation and pressure using a suite of proxy records. This WG will now work towards extending the temporal and spatial coverage of time series, and reconstruction of the large-scale climate modes that drive climate in the region.

The Arctic 2k WG was launched in 2008 and has recently produced a compilation of temperature sensitive proxies from 23 sites around the Arctic. Darrell Kaufman highlighted this synthesis and demonstrated that temperatures in the 20th century reversed a millennial-scale cooling trend. Efforts are now being directed towards the development of additional proxy records, the inclusion of discontinuous timeseries and the reconstruction of the hydroclimatic variability of the region.

The Antarctic $2 \mathrm{k}$ effort is predominantly driven by the IPICS $2 k$ project. Representing this group, Eric Steig outlined a number of recent reconstructions and modeling results for various climatic parameters. A data synthesis paper focusing on century-scale variability during the last $1 \mathrm{ka}$ is currently in progress and several projects collecting 2 ka cores have recently begun.

Eugene Wahl gave a final presentation on the importance of contributing data to international databases, such as NOAA's World Data Center for Paleoclimatology. This is particularly pertinent for large-scale syntheses such as the $2 k$ Regional Network. Eugene also outlined the variety of database tools available to researchers, and prompted discussion on ways to improve database usability and efficiency.
The $2 \mathrm{k}$ Network will produce a synthesis book, including chapters on each region and an overall global synthesis chapter. Each regional chapter will discuss the climate of a number of key periods (e.g., Medieval Climate Anomaly, Little Ice Age, Maunder Minimum), with the global signal and driving dynamical changes summarized in the global chapter.

Further details are available from the PAGES website (http://www.pages-igbp. org/science/focus2themes).

\section{References}

Bown, F.and Rivera, A., 2007: Climate changes and recent glacier behaviour in the Chilean Lake District, Global and Planetary Change, 59: 79-86.

Lara, A., Villalba, R. and Urrutia, R., 2008: A 400-year tree-ring record of the Puelo River summer-fall streamflow in the Valdivian Rainforest eco-region, Chile, Climatic Change, 86: 331-356.

Masiokas, M.H., Rivera, A., Espizua, L.E., Villalba, R., Delgado, S. and Aravena, J.C., 2009: Glacier fluctuations in extratropical South America during the past 1000 years, Palaeogeography, Palaeoclimatology, Palaeoecology, 281: 242-268.

Villalba, R., Lara, A., Boninsegna, J.A., Urrutia, R. and Masiokas, M., 2006: Tree-ring temperature reconstructions in South America revisited. PAGES/CLIVAR Workshop. Past Millennia Climate Variability: Proxy based reconstructions, Modeling and Methodology - Synthesis and Outlook, Wengen, Switzerland.

For full references please consult:

www.pages-igbp.org/products/newsletters/ref2009_3.html

\section{Young scientists meet to exchange science, network and learn about PAGES}

\section{PAGES $1^{\text {st }}$ Young Scientists Meeting - Corvallis, USA, 6-7 July 2009}

\section{Pedro DiNezio', C. Cleroux², P. Applegate ${ }^{3}$ and P. Collins ${ }^{4}$ (YSM Participants)}

${ }^{1}$ Rosenstiel School of Marine and Atmospheric Science, University of Miami, USA; pdinezio@rsmas.miami.edu; 2 Lamont-Doherty Earth Observatory, Columbia University, Palisades, USA; ${ }^{3}$ Department of Geosciences, Pennsylvania State University, University Park, USA; ${ }^{4}$ École Polytechnique Fédérale de Lausanne, Switzerland

PAGES $1^{\text {st }}$ Young Scientists Meeting (YSM) offered a platform for scientific exchange, networking and career development for more than 90 young scientists from 21 countries. The meeting also provided these young scientists with information about PAGES and other international global change organizations. The scientific program was organized around PAGES four scientific Foci; 1) Climate Forcings; 2) Regional Climate Dynamics; 3) Global Earth System Dynamics; and 4) HumanClimate-Ecosystem Interactions. In addition, several presentations were dedicated to three of PAGES four Cross-Cutting Themes (CCTs); 1) Chronology; 2) Proxy Development, Calibration and Validation; 3) Modeling.

Participants included mostly students in the later stages of their PhD and early-career PhD graduates, selected by a competitive application process. The par- ticipants contributed to oral and poster sessions, and participated in informal breakout groups and discussions. Worldclass senior scientists also participated in the meeting with special lectures. The first day started with a talk on the relevance of paleoclimate research by Nicklas Pisias (Oregon State University). He raised important questions on aspects of past climates that are relevant for issues of global warming, such as climate sensitivity to external forcing, and mechanisms of climate change and feedbacks.

Nick Pisias' presentation set the stage for the young scientists, who followed with their own talks. The talks covered cuttingedge topics in paleoclimatology, such as evaluation of mechanisms and tipping points using data and models, reconstruction of past and recent climates, exploration of assumptions made in the development of proxies, attribution of past climate changes, and modeling of past climates. A flavor of the range of research reported is given by the following (purely subjective) selection of presentations.

For PAGES Focus 1, Catalina González (University of Bremen) showed a reconstruction of rapid sea-level change associated with Heinrich events, using pollen ecology from a marine core. Her analysis of the ecological response of intertidal tropical ecosystems in the Cariaco Basin provides evidence on the timing of sealevel changes during MIS 3 and their connection with Heinrich Events, supporting the idea that sea level fluctuated along with Antarctic climate. Alberto Reyes (University of Alberta) presented a record documenting the response of permafrost to last interglacial warming. This study suggests that carbon sequestered in near-surface permafrost is likely highly vulnerable to $21^{\text {st }}$-century warming, however deeper 